\title{
PENERAPAN BIDIRECTIONAL SEARCH DAN HELD-KARP PADA PENENTUAN RUTE PENGIRIMAN PRODUK
}

\author{
I Gede Surya Rahayuda ${ }^{1}$, Ni Putu Linda Santiari², Norsa Yudhi Arso ${ }^{3}$ \\ ${ }^{1}$ Prodi Sistem Informasi, STMIK STIKOM Bali \\ ${ }^{2}$ Prodi Sistem Informasi, STMIK STIKOM Bali \\ ${ }^{3}$ Prodi Ilmu Komputer, Universitas Pendidikan Ganesha \\ Email: ${ }^{1}$ surya_rahayuda@stikom-bali.ac.id, ${ }^{2}$ linda_santiari@stikom-bali.ac.id, ${ }^{3}$ norzayudhi@icloud.com
}

(Naskah masuk 26 Juni 2018 , diterima untuk diterbitkan 29 Oktober 2018 )

\begin{abstract}
Abstrak
Bidirectional Search dan Held-Karp merupakan salah satu metode pencarian jalur terdekat atau sering disebut dengan metode shortes path. Bidirectional Search mencari jalur terdekat dengan melakukan pencarian dwi arah, proses pertama dimulai dari level awal graph matrix menuju level selanjutnya dan proses kedua dimulai dari level akhir menuju level sebelumnya. Proses tersebut akan menghasilkan rute awal dan rute akhir, kemudian kedua rute tersebut dirangkai menjadi rute gabungan. Bidirectional Search tidak memperhitungkan proses kembali dari tujuan akhir ke titik awal atau sesuai untuk non circular path. Tidak seperti pada metode Bidirectional Search, pada metode Held-Karp hanya dilakukan satu proses pencarian, dan pada metode HeldKarp proses pencarian sudah memperhitungkan mengenai jarak yang ditempuh sampai dengan kembali ke titik awal atau sesuai untuk circular path. Pada penelitian ini metode Bidirectional Search dan HeldKarp dikembangkan dalam bentuk program menggunakan bahasa pemrograman visual basic. Program tersebut diterapkan untuk menentukan jalur terbaik pada kasus pengiriman produk. Bidirectional Search juga akan dibandingkan dengan metode Held-Karp. Percobaan yang dilakukan pada beberapa data tes berupa paket pengiriman produk, didapatkan bahwa metode Held-Karp mendapatkan hasil lebih baik sekitar $5 \%$ dibandingkan dengan Bidirectional Search.
\end{abstract}

Kata kunci: shortes path, Bidirectional Search, Held-Karp, graph matrix, visual basic

\section{IMPLEMENTATION OF BIDIRECTIONAL SEARCH AND HELD-KARP ON DETERMINING PRODUCT SHIPPING ROUTE}

\begin{abstract}
Bidirectional Search and Held-Karp is one type of the shortes path methods. Bidirectional Search looks for the nearest path by doing a two way search, the first process starts from the initial level of the graph matrix to the next level and the second process starts from the end level to the previous level. The process will generate the initial route and the final route, then the two routes are assembled into a combined route. Bidirectional Search does not count the process of returning from the final destination to the starting point or appropriate for non circular paths.Unlike Bidirectional Search method, Held-Karp method only performs one way search process, and in the Held-Karp method the search process has calculated the distance traveled up to the return point or appropriate for circular paths. In this research, Bidirectional Search and Held-Karp method will be developed into desktop program using visual basic programming language. The program is implemented to determine the best path in case of product delivery. Bidirectional Search will also be compared to the Held-Karp method. Experiments performed on some tes data in the form of product delivery package, it is found that the Held-Karp method gets the average result of better delivery route about 5\% compared to Bidirectional Search method.
\end{abstract}

Keywords: shortes path, Bidirectional Search, Held-Karp, graph matrix, visual basic

\section{PENDAHULUAN}

Pengiriman produk merupakan hal yang umum dilakukan pada setiap perusahaan. Pengiriman produk akan menjadi suatu masalah yang rumit bagi perusahaan jika pesanan terhadap produk mulai meningkat atau dalam jumlah yang besar (Rahayuda and Santiari, 2018b). Bagian distribusi akan kesulitan untuk melakukan pengiriman produk, dan 
cenderung salah dalam menentukan rute pengiriman dan dapat mengakibatkan kelebihan dalam pengeluaran biaya distribusi. Penulis ingin mengatasi permasalahan tersebut dengan cara membuat suatu program yang dapat menentukan rute pengiriman produk, sehingga didapatkan jarak terdekat atau rute pengiriman terbaik. Pada penelitian sebelumnya penulis sudah membuat suatu program desktop menggunakan bahasa pemrograman visual basic, dimana program tersebut telah berhasil menentukan rute pengiriman produk. Program dibuat menggunakan dua metode, yaitu metode Iterative Deepening Search dan metode Held-Karp (Rahayuda and Santiari, 2018b) (Moore, 2015). Dari hasil penelitian yang dilakukan, dalam beberapa pengiriman produk terdapat hasil yang sama dari kedua metode. Selisih perbedaan antara kedua metode adalah sebesar 19,66\% (Rahayuda and Santiari, 2018a) (Kelvin, 2016). Pada penelitian saat ini, penulis ingin menambahkan metode lainnya. Metode yang akan digunakan adalah metode Bidirectional Search. Penambahan metode tersebut diharapkan akan dapat menambah ragam dari hasil penelitian dan dapat dibandingkan dengan penelitian sebelumnya. Bidirectional Search akan diimplementasikan menggunakan bahasa pemrograman visual basic. Diharapkan dengan penerapan metode tersebut akan mendapatkan hasil yang lebih baik dari metode sebelumnya. Selain penambahan metode penelitian, pada penelitian ini juga akan ditambahkan data set berupa tempat atau lokasi pengiriman produk. Data set ditambahkan agar didapatkan hasil penelitian yang lebih bervariasi. Dan dapat meningkatkan kualitas hasil penelitian.

\section{KAJIAN PUSTAKA}

\subsection{Bidirectional Search}

Bidirectional Search atau pencarian dwi arah merupakan salah satu metode pencarian jalur yang menggunakan dua alur logika pencarian, yaitu pencarian front to back dan back to front. Pencarian dilakukan melalui dua arah, pencarian dari batas awal graph sampai akhir dan pencarian dari akhir graph menuju ke awal, pencarian akan berakhir ketika kedua pencarian tersebut bertemua ditengah graph (Chen et al., 2017) (Holte et al., 2017). Ira Pohl merupakan ilmuwan pertama yang mendesain dan mengembangkan metode tersebut pada tahun 1971, Bidirectional Heuristic Search merupakan versi pertama dari metode tersebut. Kemudian pada pengembangan selanjutnya Andrew Goldberg dan ilmuwan lainnya menjelaskan kondisi pengakhiran yang benar untuk versi metode Bidirectional Search pada algoritma Dijkstra (Sun, Lee and Batra, 2017).

\subsection{Held-Karp}

Metode Held-Karp, juga disebut metode Bellman Held-Karp, adalah metode pemrograman dinamis yang diusulkan pada tahun 1962 secara mandiri oleh Bellman dan Karp untuk memecahkan masalah perjalanan salesman: Traveling Salesman Problem (TSP). TSP merupakan perpanjangan dari masalah sirkuit Hamiltonian (Becker et al., 2017) (Chekuri, 2017). Masalahnya dapat digambarkan seperti menemukan tur kota $\mathrm{N}$ di suatu negara (dengan asumsi semua kota yang akan dikunjungi dapat dijangkau), tur harus mengunjungi setiap kota hanya sekali, tur harus kembali ke titik awal dan tur harus mendapatkan jarak minimum (An, Kleinberg and Shmoys, 2015). Secara umum, TSP diklasifikasikan sebagai masalah perjalanan yang simetris (sTSP), masalah salesman bepergian asimetris (aTSP), dan masalah salesman multi perjalanan (mTSP) (Rahayuda and Santiari, 2017). MTSP umumnya diperlakukan sebagai masalah routing kendaraan yang tenang atau tidak terlalu krodit (Moylett, Linden and Montanaro, 2016)

\section{METODE PENELITIAN}

Penulis melakukan observasi lapangan dan mengambil data melalui internet untuk menentukan beberapa data set berupa lokasi tempat pengiriman produk. Selain tempat lokasi pengiriman produk, penulis juga menentukan data jarak antar beberapa lokasi pengiriman produk menggunakan google map. Observasi dilakukan dengan mencatat alamat semua tempat tersebut. Jarak yang diukur adalah jarak antara toko yang satu ke toko lainnya. Titik yang digunakan adalah titik pada depan toko yang berdekatan dengan jalan, atau tempat perhentian mobil atau kendaraan yang digunakan untuk mengantarkan gas tersebut. Sebelumnya terdapat dua puluh buah data set berupa alamat dari toko, dimana alamat tersebut telah digunakan sebagai alamat tempat pengiriman produk, dan diukur jarak antar tiap alamat. Jika diukur jarak setiap toko dan antar toko, maka akan didapatkan sebanyak 800 data set yang digunakan. 800 data set tersebut telah digunakan pada penelitian sebelumnya. Alamat toko tersebut berada didaerah Denpasar dan Badung (Chentsov, Khachay and Khachay, 2016). Pada penelitian saat ini akan ditambahkan sebanyak 20 alamat pengiriman produk, dimana alamat toko dipilih pada daerah Klungkung dan Gianyar. Dengan penambahan sebanyak 20 data set baru, maka akan didapatkan sebanyak 40 data set yang akan digunakan. Dan jika semua jarak antar toko diukur maka akan didapatkan 1600 data set. Seperti terlihat pada tabel 1 dan table 2 .

Tabel 1. Data Set: Lis Toko

\begin{tabular}{ccll}
\hline id & kode_toko & \multicolumn{1}{c}{ nama_toko } & \multicolumn{1}{c}{ alamat } \\
\hline $\mathbf{1}$ & B0001 & Toko Gas Retail & Jl.Gatot Subroto \\
\hline $\mathbf{2}$ & B0002 & Wr.Pemuda & Jl.Pemuda \\
\hline
\end{tabular}


I Gede Surya dkk, Penerapan Bidirectional Search ... 551

\begin{tabular}{|c|c|c|c|}
\hline id & kode_toko & nama_toko & alamat \\
\hline 3 & B0003 & Wr.Bu Gede & Jl.Siligita \\
\hline 4 & B0004 & Wr.99 & Jl.Pendidikan \\
\hline 5 & B0005 & Wr.Ayam Betutu & Jl.Sidakarya \\
\hline 6 & B0006 & Rm.Mita Minang & Jl.Raya Pemogan \\
\hline 7 & B0007 & Juice Bar & Jl.Kebudayaan \\
\hline 8 & B0008 & Wr.Oey & Jl.Raya Kesambi \\
\hline 9 & B0009 & Wr.Sandi & Jl.Kebo Iwa \\
\hline 10 & B0010 & Toko Kue Ryo & Jl.Suradipa \\
\hline 11 & B0011 & Toko Kue Bunga & Jl.Antasura \\
\hline 12 & B0012 & Wr.65 & Jl.Wr. Supratman \\
\hline 13 & B0013 & Mac and Cheesy & Jl.Diponegoro \\
\hline 14 & B0014 & Depot 99 & Jl.Palapa \\
\hline 15 & B0015 & Vian Resto & Jl.Mertasari \\
\hline 16 & B0016 & Café Bu Novi & Jl.Pratama \\
\hline 17 & B0017 & Man Shed & Jl.Tirtanadi \\
\hline 18 & B0018 & Indonesian Resto & Jl.Katrangan \\
\hline 19 & B0019 & Wr.Betutu Bu Lina & JI.Mahendradatta \\
\hline 20 & B0020 & Confiture de Bali & Jl.Merdeka \\
\hline 21 & B0021 & Smoke House & Jl.Nirarta \\
\hline 22 & B0022 & Depot Serasi & Jl.Mawar \\
\hline 23 & B0023 & Rm.Rinjani & Jl.Gn.Rinjani \\
\hline 24 & B0024 & Wr.DC & Jl.Puputan \\
\hline 25 & B0025 & Papilas Coffee & Jl.Ngurah Rai \\
\hline 26 & B0026 & Rm.Kumendel & Jl.Raya Goa Lawah \\
\hline 27 & B0027 & Sukia Bar & Jl.Raya Gelgel \\
\hline 28 & B0028 & Balawa & JI.Kresna \\
\hline 29 & B0029 & Wr.Jumpung & Jl.Rama \\
\hline 30 & B0030 & Ayu Café & Jl.Flamboyan \\
\hline 31 & B0031 & Ngerodok Resto & Jl.Mulawarman \\
\hline 32 & B0032 & Dora Resto & Jl.Patih Jelantik \\
\hline 33 & B0033 & Standing Stone & Jl.Pantai Purnama \\
\hline 34 & B0034 & Wr.Mika & Jl.Raya Batu Bulan \\
\hline 35 & B0035 & Wr.Legong & Jl.Prof.IB.Mantra \\
\hline 36 & B0036 & Petani Resto & Jl.Hanoman \\
\hline 37 & B0037 & Kismet Resto & Jl.Gaotama Selatan \\
\hline 38 & B0038 & Dharma Giri Resto & Jl.Dharma Giri \\
\hline 39 & B0039 & Kasava Resto & Jl.Raya Nyuh Kuning \\
\hline 40 & B0040 & Pangkon Bali Resto & Jl.Tirta \\
\hline
\end{tabular}

\begin{tabular}{|c|c|c|c|c|c|c|}
\hline no & awal & tujuan & waktu & jarak & biaya & litter \\
\hline 1551 & B0039 & B0031 & $32 \mathrm{~m}$ & $14 \mathrm{~km}$ & Rp. 14,263 & 2 It \\
\hline 1552 & B0039 & B0032 & $27 \mathrm{~m}$ & $9 \mathrm{~km}$ & Rp. 8,761 & $1 \mathrm{It}$ \\
\hline 1553 & B0039 & B0033 & $31 \mathrm{~m}$ & $13 \mathrm{~km}$ & Rp. 13,244 & $2 \mathrm{It}$ \\
\hline 1554 & B0039 & B0034 & $24 \mathrm{~m}$ & $12 \mathrm{~km}$ & Rp. 12,225 & 2 It \\
\hline 1555 & B0039 & B0035 & $38 \mathrm{~m}$ & $17 \mathrm{~km}$ & Rp. 17,319 & $2 \mathrm{It}$ \\
\hline 1556 & B0039 & B0036 & $19 \mathrm{~m}$ & $3 \mathrm{~km}$ & Rp. 3,362 & $0 \mathrm{It}$ \\
\hline 1557 & B0039 & B0037 & $19 \mathrm{~m}$ & $3 \mathrm{~km}$ & Rp. 3,260 & $0 \mathrm{It}$ \\
\hline 1558 & B0039 & B0038 & $26 \mathrm{~m}$ & $9 \mathrm{~km}$ & Rp. 9,271 & $1 \mathrm{It}$ \\
\hline 1559 & B0039 & B0039 & $0 \mathrm{~m}$ & $0 \mathrm{~km}$ & Rp. 0 & $0 \mathrm{It}$ \\
\hline 1560 & B0039 & B0040 & $21 \mathrm{~m}$ & $6 \mathrm{~km}$ & Rp. 6,214 & $1 \mathrm{It}$ \\
\hline 1561 & B0040 & B0001 & $55 \mathrm{~m}$ & $24 \mathrm{~km}$ & Rp. 24,450 & $3 \mathrm{It}$ \\
\hline 1562 & B0040 & B0002 & $1,440 \mathrm{~m}$ & $28 \mathrm{~km}$ & Rp. 28,525 & $4 \mathrm{It}$ \\
\hline 1563 & B0040 & B0003 & $1,464 \mathrm{~m}$ & $45 \mathrm{~km}$ & Rp. 45,844 & $6 \mathrm{It}$ \\
\hline 1564 & B0040 & B0004 & $1,451 \mathrm{~m}$ & $34 \mathrm{~km}$ & Rp. 34,638 & $4 \mathrm{It}$ \\
\hline 1565 & B0040 & B0005 & $1,450 \mathrm{~m}$ & $34 \mathrm{~km}$ & Rp. 34,638 & $4 \mathrm{It}$ \\
\hline 1566 & B0040 & B0006 & $1,456 \mathrm{~m}$ & $37 \mathrm{~km}$ & Rp. 37,694 & $5 \mathrm{It}$ \\
\hline 1567 & B0040 & B0007 & $1,448 \mathrm{~m}$ & $33 \mathrm{~km}$ & Rp. 33,619 & $4 \mathrm{It}$ \\
\hline 1568 & B0040 & B0008 & $1,446 \mathrm{~m}$ & $29 \mathrm{~km}$ & Rp. 29,544 & $4 \mathrm{It}$ \\
\hline 1569 & B0040 & B0009 & $35 \mathrm{~m}$ & $13 \mathrm{~km}$ & Rp. 13,244 & $2 \mathrm{It}$ \\
\hline 1570 & B0040 & B0010 & $48 \mathrm{~m}$ & $21 \mathrm{~km}$ & Rp. 21,394 & $3 \mathrm{It}$ \\
\hline 1571 & B0040 & B0011 & $45 \mathrm{~m}$ & $19 \mathrm{~km}$ & Rp. 19,356 & $2 \mathrm{It}$ \\
\hline 1572 & B0040 & B0012 & $54 \mathrm{~m}$ & $22 \mathrm{~km}$ & Rp. 22,413 & $3 \mathrm{It}$ \\
\hline 1573 & B0040 & B0013 & $54 \mathrm{~m}$ & $24 \mathrm{~km}$ & Rp. 24,450 & $3 \mathrm{It}$ \\
\hline 1574 & B0040 & B0014 & $1,451 \mathrm{~m}$ & $34 \mathrm{~km}$ & Rp. 34,638 & $4 \mathrm{It}$ \\
\hline 1575 & B0040 & B0015 & $1,443 \mathrm{~m}$ & $30 \mathrm{~km}$ & Rp. 30,563 & $4 \mathrm{It}$ \\
\hline 1576 & B0040 & B0016 & $1,468 \mathrm{~m}$ & $48 \mathrm{~km}$ & Rp. 48,900 & $6 \mathrm{It}$ \\
\hline 1577 & B0040 & B0017 & $1,445 \mathrm{~m}$ & $32 \mathrm{~km}$ & Rp. 32,600 & $4 \mathrm{It}$ \\
\hline 1578 & B0040 & B0018 & $53 \mathrm{~m}$ & $22 \mathrm{~km}$ & Rp. 22,413 & $3 \mathrm{It}$ \\
\hline 1579 & B0040 & B0019 & $1,444 \mathrm{~m}$ & $28 \mathrm{~km}$ & Rp. 28,525 & $4 \mathrm{It}$ \\
\hline 1580 & B0040 & B0020 & $57 \mathrm{~m}$ & $24 \mathrm{~km}$ & Rp. 24,450 & $3 \mathrm{It}$ \\
\hline 1581 & B0040 & B0021 & $52 \mathrm{~m}$ & $24 \mathrm{~km}$ & Rp. 24,450 & $3 \mathrm{It}$ \\
\hline 1582 & B0040 & B0022 & $52 \mathrm{~m}$ & $24 \mathrm{~km}$ & Rp. 24,450 & $3 \mathrm{It}$ \\
\hline 1583 & B0040 & B0023 & $53 \mathrm{~m}$ & $24 \mathrm{~km}$ & Rp. 24,450 & $3 \mathrm{It}$ \\
\hline 1584 & B0040 & B0024 & $50 \mathrm{~m}$ & $23 \mathrm{~km}$ & Rp. 23,431 & $3 \mathrm{It}$ \\
\hline 1585 & B0040 & B0025 & $51 \mathrm{~m}$ & $24 \mathrm{~km}$ & Rp. 24,450 & $3 \mathrm{It}$ \\
\hline 1586 & B0040 & B0026 & $1,441 \mathrm{~m}$ & $32 \mathrm{~km}$ & Rp. 32,600 & $4 \mathrm{It}$ \\
\hline 1587 & B0040 & B0027 & $49 \mathrm{~m}$ & $22 \mathrm{~km}$ & Rp. 22,413 & $3 \mathrm{It}$ \\
\hline 1588 & B0040 & B0028 & $1,440 \mathrm{~m}$ & $31 \mathrm{~km}$ & Rp. 31,581 & $4 \mathrm{It}$ \\
\hline 1589 & B0040 & B0029 & $57 \mathrm{~m}$ & $28 \mathrm{~km}$ & Rp. 28,525 & $4 \mathrm{It}$ \\
\hline 1590 & B0040 & B0030 & $49 \mathrm{~m}$ & $23 \mathrm{~km}$ & Rp. 23,431 & $3 \mathrm{It}$ \\
\hline 1591 & B0040 & B0031 & $37 \mathrm{~m}$ & $15 \mathrm{~km}$ & Rp. 15,281 & 2 It \\
\hline 1592 & B0040 & B0032 & $30 \mathrm{~m}$ & $12 \mathrm{~km}$ & Rp. 12,225 & $2 \mathrm{It}$ \\
\hline 1593 & B0040 & B0033 & $38 \mathrm{~m}$ & $17 \mathrm{~km}$ & Rp. 17,319 & $2 \mathrm{It}$ \\
\hline 1594 & B0040 & B0034 & $39 \mathrm{~m}$ & $17 \mathrm{~km}$ & Rp. 17,319 & 2 It \\
\hline 1595 & B0040 & B0035 & $46 \mathrm{~m}$ & $20 \mathrm{~km}$ & Rp. 20,375 & $3 \mathrm{It}$ \\
\hline 1596 & B0040 & B0036 & $14 \mathrm{~m}$ & $4 \mathrm{~km}$ & Rp. 3,871 & $0 \mathrm{lt}$ \\
\hline 1597 & B0040 & B0037 & $13 \mathrm{~m}$ & $4 \mathrm{~km}$ & Rp. 3,769 & $0 \mathrm{It}$ \\
\hline 1598 & B0040 & B0038 & $29 \mathrm{~m}$ & $13 \mathrm{~km}$ & Rp. 13,244 & 2 It \\
\hline 1599 & B0040 & B0039 & $17 \mathrm{~m}$ & $6 \mathrm{~km}$ & Rp. 6,214 & $1 \mathrm{It}$ \\
\hline 1600 & B0040 & B0040 & $0 \mathrm{~m}$ & $0 \mathrm{~km}$ & Rp. 0 & $0 \mathrm{It}$ \\
\hline
\end{tabular}

\begin{tabular}{|c|c|c|c|c|c|c|}
\hline no & awal & tujuan & waktu & jarak & biaya & litter \\
\hline 1 & B0001 & B0001 & $0 \mathrm{~m}$ & $0 \mathrm{~km}$ & Rp. 0 & $0.0 \mathrm{lt}$ \\
\hline 2 & B0001 & B0002 & $16 \mathrm{~m}$ & $8 \mathrm{~km}$ & Rp. 8,354 & $1.0 \mathrm{lt}$ \\
\hline$\cdots$ & $\cdots$ & $\cdots$ & $\ldots$ & $\ldots$ & $\ldots$ & $\cdots$ \\
\hline$\ldots$ & $\ldots$ & $\ldots$ & $\ldots$ & $\ldots$ & $\ldots$ & $\ldots$ \\
\hline$\ldots$ & $\ldots$ & $\ldots$ & $\ldots$ & $\ldots$ & $\ldots$ & $\ldots$ \\
\hline 1537 & B0039 & B0017 & $48 \mathrm{~m}$ & $23 \mathrm{~km}$ & Rp. 23,431 & $3 \mathrm{It}$ \\
\hline 1538 & B0039 & B0018 & $38 \mathrm{~m}$ & $17 \mathrm{~km}$ & Rp. 17,319 & $2 \mathrm{It}$ \\
\hline 1539 & B0039 & B0019 & $47 \mathrm{~m}$ & $22 \mathrm{~km}$ & Rp. 22,413 & $3 \mathrm{It}$ \\
\hline 1540 & B0039 & B0020 & $42 \mathrm{~m}$ & $19 \mathrm{~km}$ & Rp. 19,356 & $2 \mathrm{It}$ \\
\hline 1541 & B0039 & B0021 & $49 \mathrm{~m}$ & $20 \mathrm{~km}$ & Rp. 20,375 & $3 \mathrm{It}$ \\
\hline 1542 & B0039 & B0022 & $49 \mathrm{~m}$ & $20 \mathrm{~km}$ & Rp. 20,375 & $3 \mathrm{It}$ \\
\hline 1543 & B0039 & B0023 & $50 \mathrm{~m}$ & $20 \mathrm{~km}$ & Rp. 20,375 & $3 \mathrm{lt}$ \\
\hline 1544 & B0039 & B0024 & $48 \mathrm{~m}$ & $19 \mathrm{~km}$ & Rp. 19,356 & $2 \mathrm{lt}$ \\
\hline 1545 & B0039 & B0025 & $49 \mathrm{~m}$ & $20 \mathrm{~km}$ & Rp. 20,375 & $3 \mathrm{It}$ \\
\hline 1546 & B0039 & B0026 & $56 \mathrm{~m}$ & $32 \mathrm{~km}$ & Rp. 32,600 & $4 \mathrm{It}$ \\
\hline 1547 & B0039 & B0027 & $47 \mathrm{~m}$ & $19 \mathrm{~km}$ & Rp. 19,356 & $2 \mathrm{It}$ \\
\hline 1548 & B0039 & B0028 & $55 \mathrm{~m}$ & $31 \mathrm{~km}$ & Rp. 31,581 & $4 \mathrm{It}$ \\
\hline 1549 & B0039 & B0029 & $54 \mathrm{~m}$ & $31 \mathrm{~km}$ & Rp. 31,581 & $4 \mathrm{It}$ \\
\hline 1550 & B0039 & B0030 & $47 \mathrm{~m}$ & $19 \mathrm{~km}$ & Rp. 19,356 & $2 \mathrm{It}$ \\
\hline
\end{tabular}


552 Jurnal Teknologi Informasi dan Ilmu Komputer (JTIIK), Vol. 5, No. 5, Oktober 2018, hlm. 549-558

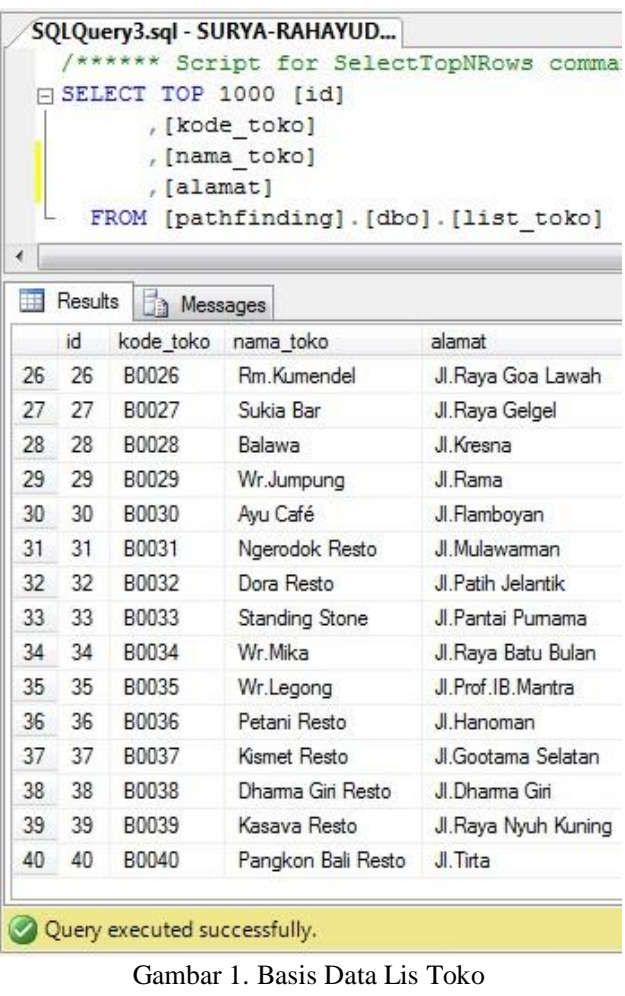

\begin{tabular}{|c|c|c|c|c|c|}
\hline \multirow{2}{*}{\multicolumn{6}{|c|}{$\begin{array}{l}\text { SQLQuery2.sqI - SURYA-RAHAYUD... } \\
\text { (t****** Script for SelectTopNRows command fr }\end{array}$}} \\
\hline & & & & & \\
\hline \multicolumn{6}{|c|}{ 曰SELECT TOP 2000 [alamat_awal] } \\
\hline \multirow{2}{*}{\multicolumn{6}{|c|}{, [alamat_akhir] }} \\
\hline & & & & & \\
\hline \multicolumn{6}{|c|}{, [waktu] } \\
\hline \multicolumn{6}{|c|}{, [jarak] } \\
\hline \multicolumn{6}{|c|}{, [biaya] } \\
\hline \multicolumn{6}{|c|}{ FROM [pathfinding] [ [dbo]. [list_rute_kirim] } \\
\hline \multicolumn{6}{|c|}{1} \\
\hline \multicolumn{6}{|c|}{ Results 首 Messages } \\
\hline & alamat_awal & alamat_akhir & waktu & jarak & biaya \\
\hline 1587 & Jl.Tita & Jl.Raya Gelgel & 49 & 22 & 22412.5 \\
\hline 1588 & Jl.Tirta & Jl.Kresna & 1440 & 31 & 31581.25 \\
\hline 1589 & Jl.Tirta & Jl.Rama & 57 & 28 & 28525 \\
\hline 1590 & Jl.Tirta & J.Flamboyan & 49 & 23 & 23431.25 \\
\hline 1591 & Jl.Tirta & Jl.Mulawarman & 37 & 15 & 15281.25 \\
\hline 1592 & Jl.Tirta & Jl.Patih Jelantik & 30 & 12 & 12225 \\
\hline 1593 & J.Tita & Jl.Pantai Pumama & 38 & 17 & 17318.75 \\
\hline 1594 & J.Tita & Jl.Raya Batu Bulan & 39 & 17 & 17318.75 \\
\hline 1595 & Jl.Tirta & JI.Prof.IB.Mantra & 46 & 20 & 20375 \\
\hline 1596 & Jl.Tirta & J.Hanoman & 14 & 3.8 & 3871.25 \\
\hline 1597 & J.Tirta & Jl.Gootama Selatan & 13 & 3.7 & 3769.375 \\
\hline 1598 & Jl.Tirta & J.Dharma Giri & 29 & 13 & 13243.75 \\
\hline 1599 & Jl.Tirta & Jl.Raya Nyuh Kuning & 17 & 6.1 & 6214.375 \\
\hline 1600 & J.Tirta & Jl.Tinta & 0 & 0 & 0 \\
\hline
\end{tabular}

Data tes akan diujicobakan pada setiap program, sehingga nantinya setiap program akan mendapatkan jalur terdekat atau jalur terbaik yang berbeda. Hasil dari setiap jalur yang didapatkan kemudian dibandingkan dan nantinya akan didapatkan hasil perbandingan dari setiap metode. Dari hasil tersebut akan dapat dianalisa dan disimpulkan metode mana yang mendapatkan hasil terbaik dan lainnya.

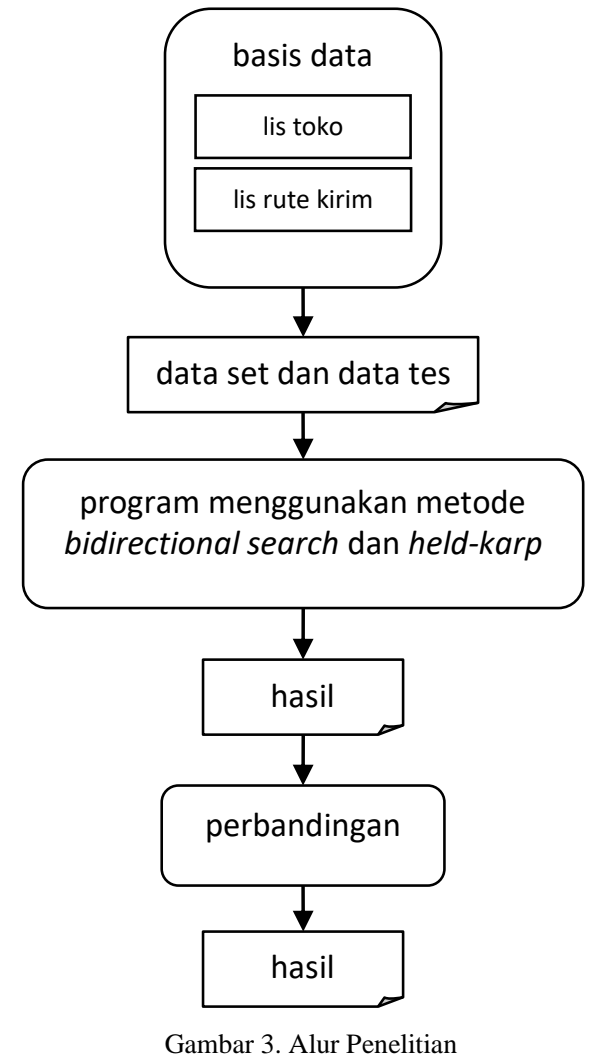

\section{IMPLEMENTASI DAN HASIL}

Program dikembangkan menggunakan bahasa pemrograman visual basic. Setelah kedua program tersebut selesai, selanjutnya dilakukan ujicoba program tersebut terhadap beberapa data tes. Terdapat 20 paket pengiriman, masing-masing paket terdiri dari 5 titik atau lokasi. Tiap titik tersebut akan diinputkan kedalam program, dan program akan memproses untuk mencari jalur terbaik dan menyusun rute pengiriman dan setiap hasil percobaan akan dicatat dan disimpan. Seperti terlihat pada gambar 4 dan 5 . Terdapat 5 buah combobox pada program, dimana nantinya admin akan memilih kode toko langganan yang melakukan pemesanan disesuaikan dengan paket pengiriman pada data tes, selanjutnya jika button jarak minimum ditekan, maka program akan memproses dan menampilkan hasil berupa: graph matrix, jarak, waktu biaya minumum dan rute tempuh terbaik yang diperoleh. Metode Bidirectional Search melakukan proses pencarian jalur terdekat dengan dua proses pencarian. Proses 1 dimulai dari level awal dari graph matrix kemudian dilanjutkan ke level kedua dan seterusnya. Disaat yang sama juga dilakukan proses 2, pencarian dimulai dari level graph matrix terakhir dan dilanjutkan ke level yang lebih kecil. Sehingga nantinya akan didapatkan rute awal dan rute akhir, rute awal dan rute akhir kemudian disatukan menjadi rute gabungan. Karena pada penelitian ini pengiriman harus kembali ke rute awal 
maka rute hasil ditambahkan dengan jarak titik akhir ke titik awal (Dramski, 2014).

Tabel 3. Matrik Bidirectional Paket Pengiriman P3

\begin{tabular}{cccccc}
\hline jarak & B0001 & B0004 & B0003 & B0023 & B0022 \\
\hline B0001 & 0 & $\mathbf{1 3}^{\text {(R1) }}$ & 30 & 29 & 28 \\
\hline B0004 & 11 & 0 & 15 & $\mathbf{3 5}^{\text {(R2) }}$ & 34 \\
\hline B0003 & 24 & 15 & 0 & 46 & $\mathbf{4 6}^{\text {(R4) }}$ \\
\hline B0023 & 30 & 35 & $\mathbf{4 6}^{\text {(R3) }}$ & 0 & 0.5 \\
\hline B0022 & 30 $^{\text {(R5) }}$ & 35 & 46 & 450 & 0 \\
\hline
\end{tabular}

Berdasarkan matrik yang diperoleh dari hasil program, dapat ditentukan :

R1 : B0001 - B0015 : $13 \mathrm{~km}$

$\mathrm{R} 2$ : B0015 - B0007 : $35 \mathrm{~km}$

R3 : B0007 - B0011 : $46 \mathrm{~km}$

$\mathrm{R} 4$ : B0011 - B0018 : $46 \mathrm{~km}$

R5 : B0018 - B0001 : $30 \mathrm{~km}$

Rute hasil $=\mathrm{R} 1+\mathrm{R} 2+\mathrm{R} 3+\mathrm{R} 4+\mathrm{R} 5=170 \mathrm{~km}$

Rute terdekat dari pengiriman P3 berdasarkan metode Bidirectional Search adalah 170 km (Zhang, Hao and Mouftah, 2014). Tidak seperti pada metode Bidirectional Search yang melakukan pencarian secara dwi arah menggunakan dua proses pencarian (Chilton, 2014). Pada metode Held-Karp hanya dilakukan satu proses pencarian (Svensson, 2015), dan pada metode Held-Karp proses pencarian sudah memperhitungkan mengenai jarak yang ditempuh sampai dengan kembali ke titik awal.

Tabel 4. Matrik Held-Karp Paket Pengiriman P3

\begin{tabular}{cccccc}
\hline jarak & B0001 & B0004 & B0003 & B0023 & B0022 \\
\hline B0001 & 0 & 13 & 30 & 29 & $\mathbf{2 8}^{\text {(R1) }}$ \\
\hline B0004 & 11 & 0 & $\mathbf{1 5}^{\text {(R3) }}$ & 35 & 34 \\
\hline B0003 & 24 & 15 & 0 & $\mathbf{4 6}^{\text {(R4) }}$ & 46 \\
\hline B0023 & $\mathbf{3 0}^{\text {(R5) }}$ & 35 & 46 & 0 & 0.5 \\
\hline B0022 & 30 & $\mathbf{3 5}^{\text {(R2) }}$ & 46 & 450 & 0
\end{tabular}

Berdasarkan matrik yang diperoleh dari hasil program, dapat ditentukan:

$\mathrm{R} 1$ : B0001 - B0022 : $28 \mathrm{~km}$

R2 : B0022 - B0004: $35 \mathrm{~km}$

$\mathrm{R} 3$ : B0004 - B0003 : $15 \mathrm{~km}$

$\mathrm{R} 4$ : B0003 - B0023 : $46 \mathrm{~km}$

R5 : B0023 - B0001 : $30 \mathrm{~km}$

Rute hasil $=\mathrm{R} 1+\mathrm{R} 2+\mathrm{R} 3+\mathrm{R} 4+\mathrm{R} 5=154 \mathrm{~km}$

Rute terdekat dari pengiriman $\mathrm{P} 3$ berdasarkan metode Held-Karp adalah 154 km (Svensson, 2015). Gambar 4, 5, 6 dan 7 merupakan ilustrasi rute pengiriman produk.

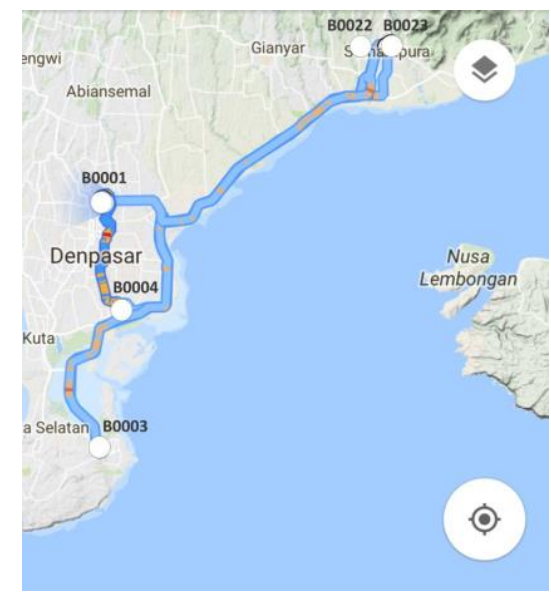

Gambar 4. Held-Karp P3 Pada Maps

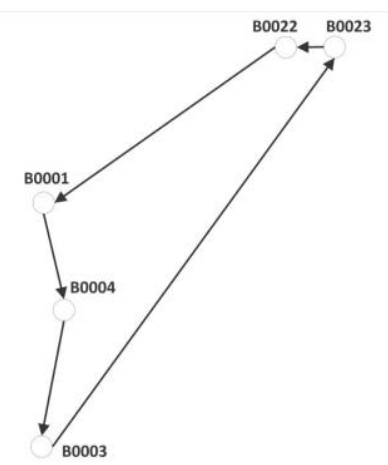

Gambar 5. Ilustrasi Held-Karp P3

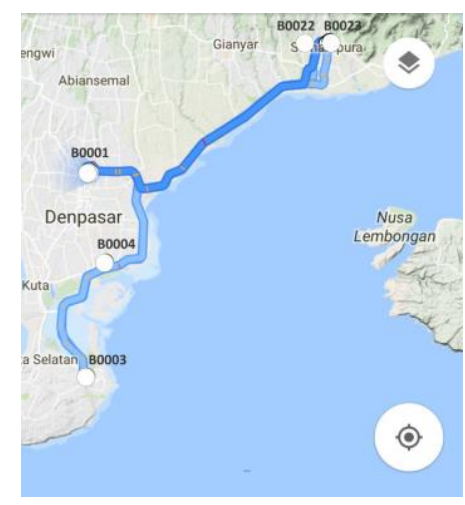

Gambar 6. Bidirectional Search P3 pada Maps

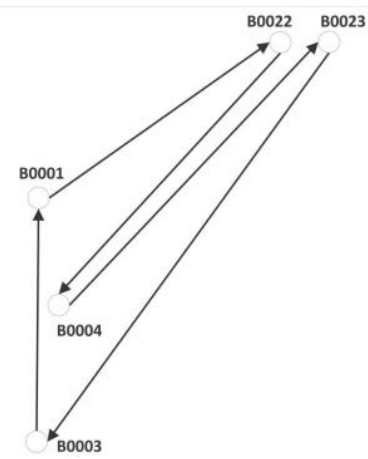

Gambar 7. Ilustrasi Bidirectional Search P3 
554 Jurnal Teknologi Informasi dan Ilmu Komputer (JTIIK), Vol. 5, No. 5, Oktober 2018, hlm. 549-558

Proses uji coba dilakukan pada 20 data tes, dari paket 1 sampai paket 20. Hasil uji coba program Bidirectional Search dan Held-Karp terlihat pada tabel 5 dan 6.

Tabel 5. Hasil Percobaan Bidirectional Search

\begin{tabular}{|c|c|c|c|c|c|}
\hline \multirow[t]{2}{*}{ Pkt } & \multicolumn{2}{|r|}{ Data Tes } & \multicolumn{3}{|c|}{ Hasil Metode Bidirectional Search } \\
\hline & $\mathbf{n}$ & nama toko & $\mathbf{n}$ & nama toko & jarak \\
\hline \multirow[t]{6}{*}{ P1 } & 1 & Toko Gas Retail & 1 & Toko Gas Retail & $88 \mathrm{Km}$ \\
\hline & 2 & Wr.Pemuda & 2 & Wr.Pemuda & \\
\hline & 3 & Confiture de Bali & 3 & Confiture de Bali & \\
\hline & 4 & Smoke House & 4 & Smoke House & \\
\hline & 5 & Pangkon Bali Resto & 5 & Pangkon Bali Resto & \\
\hline & 6 & Toko Gas Retail & 6 & Toko Gas Retail & \\
\hline \multirow[t]{6}{*}{ P2 } & 1 & Toko Gas Retail & 1 & Toko Gas Retail & $109 \mathrm{Km}$ \\
\hline & 2 & Wr.Bu Gede & 2 & Wr.Bu Gede & \\
\hline & 3 & Wr.Pemuda & 3 & Wr.Pemuda & \\
\hline & 4 & Depot Serasi & 4 & Depot Serasi & \\
\hline & 5 & Smoke House & 5 & Smoke House & \\
\hline & 6 & Toko Gas Retail & 6 & Toko Gas Retail & \\
\hline \multirow[t]{6}{*}{ P3 } & 1 & Toko Gas Retail & 1 & Toko Gas Retail & $170 \mathrm{Km}$ \\
\hline & 2 & Wr.99 & 2 & Wr.99 & \\
\hline & 3 & Wr.Bu Gede & 3 & Rm.Rinjani & \\
\hline & 4 & Rm.Rinjani & 4 & Wr.Bu Gede & \\
\hline & 5 & Depot Serasi & 5 & Depot Serasi & \\
\hline & 6 & Toko Gas Retail & 6 & Toko Gas Retail & \\
\hline \multirow[t]{6}{*}{ P4 } & 1 & Toko Gas Retail & 1 & Toko Gas Retail & $144 \mathrm{Km}$ \\
\hline & 2 & Wr.Ayam Betutu & 2 & Wr.Ayam Betutu & \\
\hline & 3 & Wr.99 & 3 & Wr.DC & \\
\hline & 4 & Wr.DC & 4 & Wr.99 & \\
\hline & 5 & Rm.Rinjani & 5 & Rm.Rinjani & \\
\hline & 6 & Toko Gas Retail & 6 & Toko Gas Retail & \\
\hline \multirow[t]{6}{*}{ P5 } & 1 & Toko Gas Retail & 1 & Toko Gas Retail & $62 \mathrm{Km}$ \\
\hline & 2 & Rm.Mita Minang & 2 & Rm.Mita Minang & \\
\hline & 3 & Wr.Ayam Betutu & 3 & Wr.Ayam Betutu & \\
\hline & 4 & Papilas Coffee & 4 & Papilas Coffee & \\
\hline & 5 & Wr.DC & 5 & Wr.DC & \\
\hline & 6 & Toko Gas Retail & 6 & Toko Gas Retail & \\
\hline \multirow[t]{6}{*}{ P6 } & 1 & Toko Gas Retail & 1 & Toko Gas Retail & $101 \mathrm{Km}$ \\
\hline & 2 & Juice Bar & 2 & Juice Bar & \\
\hline & 3 & Rm.Mita Minang & 3 & Rm.Mita Minang & \\
\hline & 4 & Rm.Kumendel & 4 & Rm.Kumendel & \\
\hline & 5 & Papilas Coffee & 5 & Papilas Coffee & \\
\hline & 6 & Toko Gas Retail & 6 & Toko Gas Retail & \\
\hline \multirow[t]{6}{*}{ P7 } & 1 & Toko Gas Retail & 1 & Toko Gas Retail & $92 \mathrm{Km}$ \\
\hline & 2 & Wr.Oey & 2 & Wr.Oey & \\
\hline & 3 & Juice Bar & 3 & Juice Bar & \\
\hline & 4 & Sukia Bar & 4 & Sukia Bar & \\
\hline & 5 & Rm.Kumendel & 5 & Rm.Kumendel & \\
\hline & 6 & Toko Gas Retail & 6 & Toko Gas Retail & \\
\hline \multirow[t]{6}{*}{ P8 } & 1 & Toko Gas Retail & 1 & Toko Gas Retail & $78 \mathrm{Km}$ \\
\hline & 2 & Wr.Sandi & 2 & Wr.Sandi & \\
\hline & 3 & Wr.Oey & 3 & Wr.Oey & \\
\hline & 4 & Balawa & 4 & Balawa & \\
\hline & 5 & Sukia Bar & 5 & Sukia Bar & \\
\hline & 6 & Toko Gas Retail & 6 & Toko Gas Retail & \\
\hline \multirow[t]{6}{*}{ P9 } & 1 & Toko Gas Retail & 1 & Toko Gas Retail & $82 \mathrm{Km}$ \\
\hline & 2 & Toko Kue Ryo & 2 & Toko Kue Ryo & \\
\hline & 3 & Wr.Sandi & 3 & Wr.Sandi & \\
\hline & 4 & Wr.Jumpung & 4 & Wr.Jumpung & \\
\hline & 5 & Balawa & 5 & Balawa & \\
\hline & 6 & Toko Gas Retail & 6 & Toko Gas Retail & \\
\hline P10 & 1 & Toko Gas Retail & 1 & Toko Gas Retail & $70 \mathrm{Km}$ \\
\hline & 2 & Toko Kue Bunga & 2 & Toko Kue Bunga & \\
\hline & 3 & Toko Kue Ryo & 3 & Toko Kue Ryo & \\
\hline & 4 & Ayu Cafe & 4 & Ayu Cafe & \\
\hline & 5 & Wr.Jumpung & 5 & Wr.Jumpung & \\
\hline & 6 & Toko Gas Retail & 6 & Toko Gas Retail & \\
\hline P11 & 1 & Toko Gas Retail & 1 & Toko Gas Retail & $71 \mathrm{Km}$ \\
\hline & 2 & Wr.65 & 2 & Wr.65 & \\
\hline & 3 & Toko Kue Bunga & 3 & Toko Kue Bunga & \\
\hline & 4 & Ngerodok Resto & 4 & Ngerodok Resto & \\
\hline & 5 & Ayu Cafe & 5 & Ayu Cafe & \\
\hline & 6 & Toko Gas Retail & 6 & Toko Gas Retail & \\
\hline
\end{tabular}

\begin{tabular}{|c|c|c|c|c|c|}
\hline \multirow[t]{2}{*}{ Pkt } & \multicolumn{2}{|r|}{ Data Tes } & \multicolumn{3}{|c|}{ Hasil Metode Bidirectional Search } \\
\hline & $\mathbf{n}$ & nama toko & $\mathrm{n}$ & nama toko & jarak \\
\hline \multirow[t]{6}{*}{ P12 } & 1 & Toko Gas Retail & 1 & Toko Gas Retail & $59 \mathrm{Km}$ \\
\hline & 2 & Mac and Cheesy & 2 & Mac and Cheesy & \\
\hline & 3 & Wr.65 & 3 & Wr.65 & \\
\hline & 4 & Dora Resto & 4 & Dora Resto & \\
\hline & 5 & Ngerodok Resto & 5 & Ngerodok Resto & \\
\hline & 6 & Toko Gas Retail & 6 & Toko Gas Retail & \\
\hline \multirow[t]{6}{*}{ P13 } & 1 & Toko Gas Retail & 1 & Toko Gas Retail & $72 \mathrm{Km}$ \\
\hline & 2 & Depot 99 & 2 & Depot 99 & \\
\hline & 3 & Mac and Cheesy & 3 & Mac and Cheesy & \\
\hline & 4 & Standing Stone & 4 & Standing Stone & \\
\hline & 5 & Dora Resto & 5 & Dora Resto & \\
\hline & 6 & Toko Gas Retail & 6 & Toko Gas Retail & \\
\hline \multirow[t]{6}{*}{ P14 } & 1 & Toko Gas Retail & 1 & Toko Gas Retail & $57 \mathrm{Km}$ \\
\hline & 2 & Vian Resto & 2 & Vian Resto & \\
\hline & 3 & Wr.Mika & 3 & Wr.Mika & \\
\hline & 4 & Standing Stone & 4 & Standing Stone & \\
\hline & 5 & Mac and Cheesy & 5 & Mac and Cheesy & \\
\hline & 6 & Toko Gas Retail & 6 & Toko Gas Retail & \\
\hline \multirow[t]{6}{*}{ P15 } & 1 & Toko Gas Retail & 1 & Toko Gas Retail & $97 \mathrm{Km}$ \\
\hline & 2 & Cafe Bu Novi & 2 & Cafe Bu Novi & \\
\hline & 3 & Vian Resto & 3 & Vian Resto & \\
\hline & 4 & Wr.Legong & 4 & Wr.Legong & \\
\hline & 5 & Wr.Mika & 5 & Wr.Mika & \\
\hline & 6 & Toko Gas Retail & 6 & Toko Gas Retail & \\
\hline \multirow[t]{6}{*}{ P16 } & 1 & Toko Gas Retail & 1 & Toko Gas Retail & $109 \mathrm{Km}$ \\
\hline & 2 & Pangkon Bali Resto & 2 & Pangkon Bali Resto & \\
\hline & 3 & Cafe Bu Novi & 3 & Cafe Bu Novi & \\
\hline & 4 & Petani Resto & 4 & Petani Resto & \\
\hline & 5 & Wr.Legong & 5 & Wr.Legong & \\
\hline & 6 & Toko Gas Retail & 6 & Toko Gas Retail & \\
\hline \multirow[t]{6}{*}{ P17 } & 1 & Toko Gas Retail & 1 & Toko Gas Retail & $56 \mathrm{Km}$ \\
\hline & 2 & Indonesian Resto & 2 & Indonesian Resto & \\
\hline & 3 & Pangkon Bali Resto & 3 & Pangkon Bali Resto & \\
\hline & 4 & Kismet Resto & 4 & Kismet Resto & \\
\hline & 5 & Petani Resto & 5 & Petani Resto & \\
\hline & 6 & Toko Gas Retail & 6 & Toko Gas Retail & \\
\hline \multirow[t]{6}{*}{ P18 } & 1 & Toko Gas Retail & 1 & Toko Gas Retail & $67 \mathrm{Km}$ \\
\hline & 2 & Wr.Betutu Bu Lina & 2 & Wr.Betutu Bu Lina & \\
\hline & 3 & Indonesian Resto & 3 & Indonesian Resto & \\
\hline & 4 & Dharma Giri Resto & 4 & Dharma Giri Resto & \\
\hline & 5 & Kismet Resto & 5 & Kismet Resto & \\
\hline & 6 & Toko Gas Retail & 6 & Toko Gas Retail & \\
\hline \multirow[t]{6}{*}{ P19 } & 1 & Toko Gas Retail & 1 & Toko Gas Retail & $70 \mathrm{Km}$ \\
\hline & 2 & Confiture de Bali & 2 & Confiture de Bali & \\
\hline & 3 & Wr.Betutu Bu Lina & 3 & Wr.Betutu Bu Lina & \\
\hline & 4 & Kasava Resto & 4 & Kasava Resto & \\
\hline & 5 & Dharma Giri Resto & 5 & Dharma Giri Resto & \\
\hline & 6 & Toko Gas Retail & 6 & Toko Gas Retail & \\
\hline \multirow[t]{6}{*}{ P20 } & 1 & Toko Gas Retail & 1 & Toko Gas Retail & $58 \mathrm{Km}$ \\
\hline & 2 & Wr.Pemuda & 2 & Wr.Pemuda & \\
\hline & 3 & Confiture de Bali & 3 & Confiture de Bali & \\
\hline & 4 & Pangkon Bali Resto & 4 & Pangkon Bali Resto & \\
\hline & 5 & Kasava Resto & 5 & Kasava Resto & \\
\hline & 6 & Toko Gas Retail & 6 & Toko Gas Retail & \\
\hline
\end{tabular}

Tabel 6. Hasil Percobaan Held-Karp

\begin{tabular}{cclcll}
\hline Pkt & \multicolumn{3}{c}{ Data Tes } & \multicolumn{2}{c}{ Hasil Metode Held-Karp } \\
\cline { 2 - 6 } & $\mathbf{n}$ & \multicolumn{1}{c}{ nama toko } & $\mathbf{n}$ & \multicolumn{1}{c}{ nama toko } & jarak \\
\hline P1 & 1 & Toko Gas Retail & 1 & Toko Gas Retail & $83 \mathrm{Km}$ \\
& 2 & Wr.Pemuda & 2 & Pangkon Bali Resto & \\
& 3 & Confiture de Bali & 3 & Smoke House & \\
& 4 & Smoke House & 4 & Wr.Pemuda & \\
& 5 & Pangkon Bali Resto & 5 & Confiture de Bali & \\
& 6 & Toko Gas Retail & 6 & Toko Gas Retail & \\
\hline P2 & 1 & Toko Gas Retail & 1 & Toko Gas Retail & $100 \mathrm{Km}$ \\
& 2 & Wr.Bu Gede & 2 & Smoke House & \\
& 3 & Wr.Pemuda & 3 & Depot Serasi & \\
& 4 & Depot Serasi & 4 & Wr.Bu Gede & \\
& 5 & Smoke House & 5 & Wr.Pemuda & \\
& 6 & Toko Gas Retail & 6 & Toko Gas Retail & \\
& & & &
\end{tabular}


I Gede Surya dkk, Penerapan Bidirectional Search ... 555

\begin{tabular}{|c|c|c|c|c|c|}
\hline \multirow[t]{2}{*}{ Pkt } & \multicolumn{2}{|r|}{ Data Tes } & \multicolumn{3}{|c|}{ Hasil Metode Held-Karp } \\
\hline & $\mathbf{n}$ & nama toko & $\mathbf{n}$ & nama toko & jarak \\
\hline \multirow[t]{6}{*}{ P3 } & 1 & Toko Gas Retail & 1 & Toko Gas Retail & $154 \mathrm{Km}$ \\
\hline & 2 & Wr.99 & 2 & Depot Serasi & \\
\hline & 3 & Wr.Bu Gede & 3 & Wr.99 & \\
\hline & 4 & Rm.Rinjani & 4 & Wr.Bu Gede & \\
\hline & 5 & Depot Serasi & 5 & Rm.Rinjani & \\
\hline & 6 & Toko Gas Retail & 6 & Toko Gas Retail & \\
\hline \multirow[t]{6}{*}{ P4 } & 1 & Toko Gas Retail & 1 & Toko Gas Retail & $142 \mathrm{Km}$ \\
\hline & 2 & Wr.Ayam Betutu & 2 & Rm.Rinjani & \\
\hline & 3 & Wr.99 & 3 & Wr.Ayam Betutu & \\
\hline & 4 & Wr.DC & 4 & Wr.DC & \\
\hline & 5 & Rm.Rinjani & 5 & Wr.99 & \\
\hline & 6 & Toko Gas Retail & 6 & Toko Gas Retail & \\
\hline \multirow[t]{6}{*}{ P5 } & 1 & Toko Gas Retail & 1 & Toko Gas Retail & $81 \mathrm{Km}$ \\
\hline & 2 & Rm.Mita Minang & 2 & Wr.DC & \\
\hline & 3 & Wr.Ayam Betutu & 3 & Papilas Coffee & \\
\hline & 4 & Papilas Coffee & 4 & Wr.Ayam Betutu & \\
\hline & 5 & Wr.DC & 5 & Rm.Mita Minang & \\
\hline & 6 & Toko Gas Retail & 6 & Toko Gas Retail & \\
\hline \multirow[t]{6}{*}{ P6 } & 1 & Toko Gas Retail & 1 & Toko Gas Retail & $92 \mathrm{Km}$ \\
\hline & 2 & Juice Bar & 2 & Papilas Coffee & \\
\hline & 3 & Rm.Mita Minang & 3 & Rm.Kumendel & \\
\hline & 4 & Rm.Kumendel & 4 & Juice Bar & \\
\hline & 5 & Papilas Coffee & 5 & Rm.Mita Minang & \\
\hline & 6 & Toko Gas Retail & 6 & Toko Gas Retail & \\
\hline \multirow[t]{6}{*}{ P7 } & 1 & Toko Gas Retail & 1 & Toko Gas Retail & $93 \mathrm{Km}$ \\
\hline & 2 & Wr.Oey & 2 & Rm.Kumendel & \\
\hline & 3 & Juice Bar & 3 & Sukia Bar & \\
\hline & 4 & Sukia Bar & 4 & Juice Bar & \\
\hline & 5 & Rm.Kumendel & 5 & Wr.Oey & \\
\hline & 6 & Toko Gas Retail & 6 & Toko Gas Retail & \\
\hline \multirow[t]{6}{*}{ P8 } & 1 & Toko Gas Retail & 1 & Toko Gas Retail & $64 \mathrm{Km}$ \\
\hline & 2 & Wr.Sandi & 2 & Sukia Bar & \\
\hline & 3 & Wr.Oey & 3 & Balawa & \\
\hline & 4 & Balawa & 4 & Wr.Sandi & \\
\hline & 5 & Sukia Bar & 5 & Wr.Oey & \\
\hline & 6 & Toko Gas Retail & 6 & Toko Gas Retail & \\
\hline P9 & 1 & Toko Gas Retail & 1 & Toko Gas Retail & $60 \mathrm{Km}$ \\
\hline & 2 & Toko Kue Ryo & 2 & Balawa & \\
\hline & 3 & Wr.Sandi & 3 & Wr.Jumpung & \\
\hline & 4 & Wr.Jumpung & 4 & Wr.Sandi & \\
\hline & 5 & Balawa & 5 & Toko Kue Ryo & \\
\hline & 6 & Toko Gas Retail & 6 & Toko Gas Retail & \\
\hline P10 & 1 & Toko Gas Retail & 1 & Toko Gas Retail & $72 \mathrm{Km}$ \\
\hline & 2 & Toko Kue Bunga & 2 & Wr.Jumpung & \\
\hline & 3 & Toko Kue Ryo & 3 & Ayu Cafe & \\
\hline & 4 & Ayu Cafe & 4 & Toko Kue Bunga & \\
\hline & 5 & Wr.Jumpung & 5 & Toko Kue Ryo & \\
\hline & 6 & Toko Gas Retail & 6 & Toko Gas Retail & \\
\hline P11 & 1 & Toko Gas Retail & 1 & Toko Gas Retail & $67 \mathrm{Km}$ \\
\hline & 2 & Wr.65 & 2 & Ayu Cafe & \\
\hline & 3 & Toko Kue Bunga & 3 & Ngerodok Resto & \\
\hline & 4 & Ngerodok Resto & 4 & Toko Kue Bunga & \\
\hline & 5 & Ayu Cafe & 5 & Wr.65 & \\
\hline & 6 & Toko Gas Retail & 6 & Toko Gas Retail & \\
\hline P12 & 1 & Toko Gas Retail & 1 & Toko Gas Retail & $43 \mathrm{Km}$ \\
\hline & 2 & Mac and Cheesy & 2 & Ngerodok Resto & \\
\hline & 3 & Wr.65 & 3 & Dora Resto & \\
\hline & 4 & Dora Resto & 4 & Mac and Cheesy & \\
\hline & 5 & Ngerodok Resto & 5 & Wr.65 & \\
\hline & 6 & Toko Gas Retail & 6 & Toko Gas Retail & \\
\hline P13 & 1 & Toko Gas Retail & 1 & Toko Gas Retail & $65 \mathrm{Km}$ \\
\hline & 2 & Depot 99 & 2 & Dora Resto & \\
\hline & 3 & Mac and Cheesy & 3 & Standing Stone & \\
\hline & 4 & Standing Stone & 4 & Depot 99 & \\
\hline & 5 & Dora Resto & 5 & Mac and Cheesy & \\
\hline & 6 & Toko Gas Retail & 6 & Toko Gas Retail & \\
\hline P14 & 1 & Toko Gas Retail & 1 & Toko Gas Retail & $53 \mathrm{Km}$ \\
\hline & 2 & Vian Resto & 2 & Mac and Cheesy & \\
\hline & 3 & Wr.Mika & 3 & Vian Resto & \\
\hline & 4 & Standing Stone & 4 & Wr.Mika & \\
\hline & 5 & Mac and Cheesy & 5 & Standing Stone & \\
\hline & 6 & Toko Gas Retail & 6 & Toko Gas Retail & \\
\hline
\end{tabular}

\begin{tabular}{|c|c|c|c|c|c|}
\hline \multirow[t]{2}{*}{ Pkt } & \multicolumn{2}{|r|}{ Data Tes } & \multicolumn{3}{|c|}{ Hasil Metode Held-Karp } \\
\hline & $\mathbf{n}$ & nama toko & $\mathbf{n}$ & nama toko & jarak \\
\hline \multirow[t]{6}{*}{ P15 } & 1 & Toko Gas Retail & 1 & Toko Gas Retail & $87 \mathrm{Km}$ \\
\hline & 2 & Cafe Bu Novi & 2 & Wr.Mika & \\
\hline & 3 & Vian Resto & 3 & Wr.Legong & \\
\hline & 4 & Wr.Legong & 4 & Vian Resto & \\
\hline & 5 & Wr.Mika & 5 & Cafe Bu Novi & \\
\hline & 6 & Toko Gas Retail & 6 & Toko Gas Retail & \\
\hline \multirow[t]{6}{*}{ P16 } & 1 & Toko Gas Retail & 1 & Toko Gas Retail & $107 \mathrm{Km}$ \\
\hline & 2 & Pangkon Bali Resto & 2 & Wr.Legong & \\
\hline & 3 & Cafe Bu Novi & 3 & Petani Resto & \\
\hline & 4 & Petani Resto & 4 & Pangkon Bali Resto & \\
\hline & 5 & Wr.Legong & 5 & Cafe Bu Novi & \\
\hline & 6 & Toko Gas Retail & 6 & Toko Gas Retail & \\
\hline \multirow[t]{6}{*}{ P17 } & 1 & Toko Gas Retail & 1 & Toko Gas Retail & $61 \mathrm{Km}$ \\
\hline & 2 & Indonesian Resto & 2 & Petani Resto & \\
\hline & 3 & Pangkon Bali Resto & 3 & Kismet Resto & \\
\hline & 4 & Kismet Resto & 4 & Pangkon Bali Resto & \\
\hline & 5 & Petani Resto & 5 & Indonesian Resto & \\
\hline & 6 & Toko Gas Retail & 6 & Toko Gas Retail & \\
\hline \multirow[t]{6}{*}{ P18 } & 1 & Toko Gas Retail & 1 & Toko Gas Retail & $70 \mathrm{Km}$ \\
\hline & 2 & Wr.Betutu Bu Lina & 2 & Kismet Resto & \\
\hline & 3 & Indonesian Resto & 3 & Dharma Giri Resto & \\
\hline & 4 & Dharma Giri Resto & 4 & Indonesian Resto & \\
\hline & 5 & Kismet Resto & 5 & Wr.Betutu Bu Lina & \\
\hline & 6 & Toko Gas Retail & 6 & Toko Gas Retail & \\
\hline \multirow[t]{6}{*}{ P19 } & 1 & Toko Gas Retail & 1 & Toko Gas Retail & $68 \mathrm{Km}$ \\
\hline & 2 & Confiture de Bali & 2 & Dharma Giri Resto & \\
\hline & 3 & Wr.Betutu Bu Lina & 3 & Kasava Resto & \\
\hline & 4 & Kasava Resto & 4 & Confiture de Bali & \\
\hline & 5 & Dharma Giri Resto & 5 & Wr.Betutu Bu Lina & \\
\hline & 6 & Toko Gas Retail & 6 & Toko Gas Retail & \\
\hline \multirow[t]{6}{*}{ P20 } & 1 & Toko Gas Retail & 1 & Toko Gas Retail & $57 \mathrm{Km}$ \\
\hline & 2 & Wr.Pemuda & 2 & Kasava Resto & \\
\hline & 3 & Confiture de Bali & 3 & Pangkon Bali Resto & \\
\hline & 4 & Pangkon Bali Resto & 4 & Confiture de Bali & \\
\hline & 5 & Kasava Resto & 5 & Wr.Pemuda & \\
\hline & 6 & Toko Gas Retail & 6 & Toko Gas Retail & \\
\hline
\end{tabular}

Dari hasil percobaan tersebut dapat dilihat bahwa sebagian besar metode Held-Karp dapat menentukan jalur yang lebih dekat dibandingkan dengan metode Bidirectional Search.

Tabel 7. Perbandingan Bidirectional dan Held-Karp

\begin{tabular}{cccrr}
\hline Paket & Held-Karp & Bidirectional & \multicolumn{2}{c}{ Selisih Perbedaan } \\
\cline { 2 - 5 } & jarak & jarak & jarak & $\%$ \\
\hline P1 & $83 \mathrm{Km}$ & $88 \mathrm{Km}$ & $5 \mathrm{Km}$ & $6 \%$ \\
\hline P2 & $100 \mathrm{Km}$ & $109 \mathrm{Km}$ & $9 \mathrm{Km}$ & $8 \%$ \\
\hline P3 & $154 \mathrm{Km}$ & $170 \mathrm{Km}$ & $16 \mathrm{Km}$ & $9 \%$ \\
\hline P4 & $142 \mathrm{Km}$ & $144 \mathrm{Km}$ & $2 \mathrm{Km}$ & $1 \%$ \\
\hline P5 & $81 \mathrm{Km}$ & $62 \mathrm{Km}$ & $-19 \mathrm{Km}$ & $-31 \%$ \\
\hline P6 & $92 \mathrm{Km}$ & $101 \mathrm{Km}$ & $9 \mathrm{Km}$ & $9 \%$ \\
\hline P7 & $93 \mathrm{Km}$ & $92 \mathrm{Km}$ & $-1 \mathrm{Km}$ & $-1 \%$ \\
\hline P8 & $64 \mathrm{Km}$ & $78 \mathrm{Km}$ & $14 \mathrm{Km}$ & $18 \%$ \\
\hline P9 & $60 \mathrm{Km}$ & $82 \mathrm{Km}$ & $22 \mathrm{Km}$ & $27 \%$ \\
\hline P10 & $72 \mathrm{Km}$ & $70 \mathrm{Km}$ & $-2 \mathrm{Km}$ & $-3 \%$ \\
\hline P11 & $67 \mathrm{Km}$ & $71 \mathrm{Km}$ & $4 \mathrm{Km}$ & $6 \%$ \\
\hline P12 & $43 \mathrm{Km}$ & $59 \mathrm{Km}$ & $16 \mathrm{Km}$ & $27 \%$ \\
\hline P13 & $65 \mathrm{Km}$ & $72 \mathrm{Km}$ & $7 \mathrm{Km}$ & $10 \%$ \\
\hline P14 & $53 \mathrm{Km}$ & $57 \mathrm{Km}$ & $4 \mathrm{Km}$ & $7 \%$ \\
\hline P15 & $87 \mathrm{Km}$ & $97 \mathrm{Km}$ & $10 \mathrm{Km}$ & $10 \%$ \\
\hline P16 & $107 \mathrm{Km}$ & $109 \mathrm{Km}$ & $2 \mathrm{Km}$ & $2 \%$ \\
\hline P17 & $61 \mathrm{Km}$ & $56 \mathrm{Km}$ & $-5 \mathrm{Km}$ & $-9 \%$ \\
\hline P18 & $70 \mathrm{Km}$ & $67 \mathrm{Km}$ & $-3 \mathrm{Km}$ & $-4 \%$ \\
\hline P19 & $68 \mathrm{Km}$ & $70 \mathrm{Km}$ & $2 \mathrm{Km}$ & $3 \%$ \\
\hline P20 & $57 \mathrm{Km}$ & $58 \mathrm{Km}$ & $1 \mathrm{Km}$ & $2 \%$ \\
\hline & Selisih total dan persentase & $\mathbf{5} \%$ \\
\hline & & & & \\
\hline Pm & & & \\
\hline
\end{tabular}


Walaupun sebagian besar hasil percobaan metode Held-Karp lebih baik dibandingkan dengan metode Bidirectional Search, namun pada beberapa kasus pengiriman, metode Bidirectional Search mendapatkan hasi yang lebih baik. Dari tabel perbandingan tersebut dapat dilihat bahwa metode Bidirectional Search mendapatkan hasil yang lebih baik pada paket pengiriman P5, P7, P10, P17 dan P18. Sedangkan metode Held-Karp mendapatkan hasil yang lebih baik pada paket pengiriman P1 sampai dengan P5, P8 sampai dengan P16, P19 dan P20.

Dari hasil percobaan tersebut, jika dilakukan kalkulasi secara keseluruhan, dapat dikatakan metode Held-Karp dapat menentukan jalur yang lebih baik dibandingkan dengan metode Bidirectional Search, Held-Karp mendapatkan hasil yang lebih baik sebesar $5 \%$ dibandingkan dengan metode Bidirectional Search. Jika digambarkan dalam bentuk chart maka akan terlihat seperti pada gambar 8 .

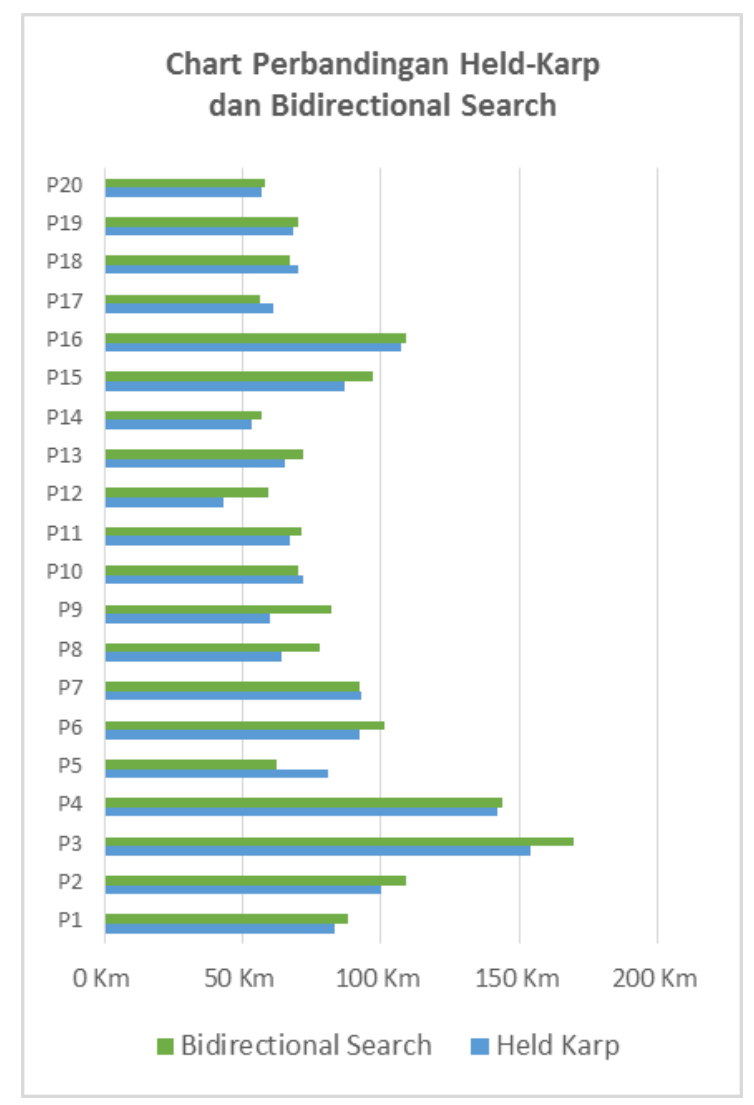

Gambar 8. Chart Perbandingan Bidirectional Search dan HeldKarp

\section{KESIMPULAN}

Metode Bidirectional Search dan Held-Karp berhasil diimplementasikan menggunakan bahasa pemrograman visual basic. Dari uji coba terhadap beberapa data tes, diketahui Held-Karp mendapatkan hasil $5 \%$ lebih baik dari Bidirectional Search. Dari beberapa penelitian yang dilakukan, dapat disimpulkan metode Held-Karp lebih tepat diterapkan untuk kasus pengiriman produk yang memerlukan perjalanan kembali ke titik awal setelah semua titik terkunjungi (Islam, Narayanan and Likhachev, 2016). Metode Bidirectional Search akan lebih baik jika diterapkan pada kasus yang tidak memerlukan perjalanan kembali ke titik awal dan akan mendapatkan hasil optimal jika diterapkan pada kasus pengiriman yang memiliki data titik dengan jarak berdekatan di level awal dan akhir matrik (Sturtevant and Chen, 2016), dan memiliki titik yang berjauahan di level tengah dari graph matrik (Kucherov, Salikhov and Tsur, 2014).

\section{DAFTAR PUSTAKA}

AN, H.-C., KLEINBERG, R. and SHMOYS, D.B., 2015. Improving Christofides' Algorithm for the s-t Path TSP. Journal of the ACM, 62(5), pp.1-28.

BECKER, A., FOX-EPSTEIN, E., KLEIN, P.N. and MEIERFRANKENFELD, D., 2017. Engineering an Approximation Scheme for Traveling Salesman in Planar Graphs *. (8), pp.1-8.

CHEKURI, C., 2017. Approximating the Held-Karp Bound for Metric TSP in Nearly Linear Time *. In: 58th Annual IEEE Symposium on Foundations of Computer Science.

CHEN, J., HOLTE, R.C., ZILLES, S. and STURTEVANT, N.R., 2017. Front-to-End Bidirectional Heuristic Search with NearOptimal Node Expansions.

CHENTSOV, A., KHACHAY, M. and KHACHAY, D., 2016. Linear time algorithm for Precedence Constrained Asymmetric Generalized Traveling Salesman Problem. IFAC-PapersOnLine, 49(12), pp.651-655.

CHILTON, M.A., 2014. Resource allocation in IT projects: Using schedule optimization. International Journal of Information Systems and Project Management, 2(3), pp.47-59.

DRAMSKI, M., 2014. Bi-directional search in route planning in navigation. Scientific Journals Maritime University of Szczecin, 39(111), pp.57-62.

HOLTE, R.C., FELNER, A., SHARON, G., STURTEVANT, N.R. and CHEN, J., 2017. MM: A bidirectional search algorithm that is guaranteed to meet in the middle. Artificial Intelligence, 252, pp.232-266.

ISLAM, F., NARAYANAN, V. and LIKHACHEV, M., 2016. A*-Connect: Bounded suboptimal bidirectional heuristic search. In: Proceedings IEEE International Conference on Robotics and Automation. pp.2752-2758.

KELVIN, A., 2016. Aplikasi Program Dinamis dalam Pemecahan TSP. Jurnal Ilmu Komputer dan Informasi. 
KUCHEROV, G., SALIKHOV, K. and TSUR, D., 2014. Approximate String Matching Using a Bidirectional Index. Combinatorial pattern matching, 8486, pp.222-231.

MOORE, T., 2015. Implementing the Held-Karp Lower Bound Algorithm in Python. In: Final Report for CM2SC 4515 - Honors Option.

MOYLETT, D.J., LINDEN, N. and MONTANARO, A., 2016. Quantum speedup of the Travelling Salesman Problem for boundeddegree graphs. pp.1-12.

RAHAYUDA, I.G.S. and SANTIARI, N.P.L., 2017. Penerapan Pemrograman Dinamis Pada Manajemen Pengiriman Produk Menggunakan Metode Held-Karp. In: Konferensi Nasional Sistem \& Informatika 2017. pp.513-518.

RAHAYUDA, I.G.S. and SANTIARI, N.P.L., 2018a. Basis Path Testing of Iterative Deepening Search and Held-Karp on Pathfinding Algorithm. Jurnal Ilmiah Kursor, 9(2).

RAHAYUDA, I.G.S. and SANTIARI, N.P.L., 2018b. Implementasi dan Perbandingan Metode Iterative Deepening Search dan Held-Karp pada Manajemen Pengiriman Produk. Sisfo, 07(02).

STURTEVANT, N.R. and CHEN, J., 2016. External memory bidirectional search. In: IJCAI International Joint Conference on Artificial Intelligence. pp.676-682.

SUN, Q., LEE, S. and BATRA, D., 2017. Bidirectional beam search: Forward-backward inference in neural sequence models for fill-inthe-blank image captioning. In: Proceedings 30th IEEE Conference on Computer Vision and Pattern Recognition, CVPR 2017. pp.72157223.

SVENSSON, O., 2015. Symmetric Traveling Salesman Problem.

ZHANG, B., HAO, J. and MOUFTAH, H.T., 2014. Bidirectional multi-constrained routing algorithms. IEEE Transactions on Computers, 63(9), pp.2174-2186. 


\section{Halaman ini sengaja dikosongkan}

